\title{
Environmental and irrigation conditions can mask the effect of \\ Magnaporthiopsis maydis on growth and productivity of maize
}

C.M. Ortiz-Bustos ${ }^{\mathrm{a}}$, A. López-Bernal ${ }^{\mathrm{b}}$, L. Testi $^{\mathrm{a}}$, and L. Molinero-Ruiz ${ }^{\mathrm{a}}{ }^{*}$

${ }^{a}$ Institute for Sustainable Agriculture (IAS), Spanish National Research Council (CSIC),

Alameda del Obispo s/n, 14004 Córdoba, Spain.

${ }^{\mathrm{b}}$ Department of Agronomy, University of Córdoba, Campus de Rabanales, Edificio C4, 14071 Córdoba, Spain.

* E-mail: 1molinero@ ias.csic.es

ORCID digit of author A. López-Bernal: 0000-0002-1034-4718

ORCID digit of author L. Testi: 0000-0002-8728-7563

ORCID digit of author L. Molinero-Ruiz: 0000-0001-5152-0418

Running head: Maize late wilt as affected by environment and irrigation

Keywords: Cephalosporium maydis, corn, late wilt, soilborne fungus, water management, Zea mays L.

This article has been accepted for publication and undergone full peer review but has not been through the copyediting, typesetting, pagination and proofreading process, which may lead to differences between this version and the Version of Record. Please cite this article as doi: 10.1111/ppa.13070

This article is protected by copyright. All rights reserved. 


\section{Abstract}

Maize production in temperate countries is threatened by late wilt, caused by Magnaporthiopsis maydis. Plant infection occurs early after sowing, but symptoms appear from flowering onwards. The disease is mainly controlled by genetic resistance, which is often partially expressed in the field. Development of disease symptoms is also highly dependent on environmental conditions. We studied whether production and growth of susceptible maize are affected by $M$. maydis under environmental conditions that are suboptimal for disease development. In addition, the effect of water availability on disease development under optimal conditions was determined. Pot experiments were conducted in an open-air enclosure 2013, 2015 and 2016. Under unfavourable conditions for disease (low air temperature and relatively high air humidity), aboveground symptoms did not appear in the plants in spite of growth and production variables being clearly altered by the fungus. When air temperatures and humidity were optimal for disease development (air temperatures were relatively high and humidity was rather low), leaf symptoms on inoculated plants became apparent but with secondary importance compared to decreases of growth and production. Under these conditions, the pathogen also affected the root/aboveground biomass ratio to a greater extent when the plants were under good water conditions than under deficit irrigation. Under optimal conditions and with good soil water content, the infected crop may end its cycle asymptomatically, with the disease undetected, although reductions in yield and above-ground biomass can occur.

This article is protected by copyright. All rights reserved. 


\section{Introduction}

The production of maize in countries with warm to hot climates - like Spain, Portugal, Egypt and India - is yearly threatened by late wilt (El-Shafey \& Claflin, 1999; Molinero-Ruiz et al., 2010; Ortiz-Bustos et al., 2015). The disease is caused by the soilborne fungus Magnaporthiopsis maydis (synonym Cephalosporium maydis Samra, Sabet \& Hingorani) (Samra et al., 1963) and, although plant infection occurs early after sowing (Sabet et al., 1970a), wilting appears around flowering, with leaves drying up and steadily becoming brittle until maturity (Molinero-Ruiz et al., 2010).

Although the disease can be controlled using fungicides (Degani et al., 2014; 2018), environmentally friendly methods to restrict crop diseases are being encouraged in European agriculture. As such, maize late wilt is mainly controlled by means of genetic resistance, but this option is limited by the existence of a diversity of aggressive strains within M. maydis populations (Zeller et al. 2002; Ortiz-Bustos et al., 2016) and, in some cases, by a partial expression of the resistance, which greatly depends on environmental conditions (OrtizBustos et al., 2016). Besides, the consistency of biological control on a field scale has not been demonstrated (El-Mehalawy et al., 2004; Bergstrom et al., 2008). Similarly, the bioactivity of Lycium europaeum L. extracts through direct inhibition of both growth and sporulation of the pathogen, as well as by a reduction in disease development, has recently been reported, but under greenhouse conditions (Tej et al., 2018).

The effect of particular crop practices on pathogen survival in the soil and, therefore, on its infection ability, has also been studied to reduce disease severity and losses. Inoculum survival, which depends primarily on its persistence in infected crop residues, is restricted to the top $20 \mathrm{~cm}$ of soil (Sabet et al., 1970b). In some studies flood-fallowing has been shown to contribute to inoculum reduction through the increase in anaerobic conditions and consequent stimulation of lytic organisms to degrade sclerotia (Bergstrom et al., 2008). Annual 
ploughing and deep tillage can also have a detrimental effect on inoculum due to the location of sclerotia and infected crop tissues in deeper soil layers, in contrast to no-till maize systems, which can result in an inoculum build-up in the soil (Samra et al., 1966). Soil solarisation has reduced late wilt in Egypt, but its application is limited to small areas, which are not frequently used for maize production. Other cultural and management options like selection of the sowing date or water conditions can also have an influence on disease development. Early sowing of maize in Egypt reduced late wilt, while late planting reduced disease severity in India (Bergstrom et al., 2008). Frequent watering or saturated soils have been associated with reduced late wilt (Samra et al., 1966), and moisture stress is reported to be a major predisposing factor for late wilt (Abdel-Rahim et al., 1998). Degani et al. (2018) demonstrated that increasing the water supply and moving from sprinkler to drip, and increasing the volume of root system wetted under high frequency irrigation reduce severity of late wilt.

Concerning air temperature that favour late wilt development, there is a consensus that symptoms develop very fast at 20 to $32{ }^{\circ} \mathrm{C}$, with 28 to $30{ }^{\circ} \mathrm{C}$ being the optimum air temperature for disease (Sing \& Siradhana, 1987). Coincidentally, drought and high temperatures are characteristic of areas where late wilt limits maize grain production (Bergstrom et al., 2008). Plants can become predisposed to infection when they have been weakened by water deficiency, but limited water availability after the establishment of the infection can also influence subsequent disease development (Boyer, 1995). The water supply is of paramount importance when it comes to crop diseases caused by vascular pathogens, as is the case with M. maydis (Sabet et al., 1970a). Wilting can be due to biotic water stress (i.e. vascular pathogens) or to abiotic water stress imposed by a low water supply to the crop, and both factors can even occur together (Hall \& MacHardy, 1981; MacElrone et al., 2001; Ochola et al., 2015). 
In this research, we studied whether maize production is affected by $M$. maydis under conditions that are not optimal for the development of visual late wilt symptoms (mild air temperature and relatively high air humidity). The maize growth variables most importantly affected by the pathogen were also assessed. Finally, the effect that water availability may have on the development of late wilt in maize was explored.

\section{Materials and methods}

In this work the effect of $M$. maydis on the growth and yield of maize plants grown in pots and in an open-air enclosure during the whole growing season was studied in four experiments. Two of these experiments were conducted in Spring 2013 and 2016 (experiments Spring-2013 and Spring-2016). The meteorological conditions during these two experiments were sub-optimal for late wilt. The other two experiments, conducted in Spring 2015 (experiment Spring-2015) and Summer 2016 (experiment Summer-2016), were characterized by warm and dry conditions that are very favourable conditions for disease development.

Effect of Magnaporthiopsis maydis on maize under conditions sub-optimal for late wilt

The effect of M. maydis on the growth and development of maize plants during the whole growing season was studied under the semi-natural conditions of an open-air enclosure in Spring 2013 (experiment Spring-2013) and 2016 (experiment Spring-2016). These experiments were carried out under relatively cool and not very dry meteorological conditions (Table 1), which are, due to low air temperature and relatively high air humidity, sub-optimal conditions for the infection and/or the development of the symptoms (Singh \& 
Siradhana, 1987; Ortiz-Bustos et al., 2016). The methodology used for plant inoculation and growth was similar to that of Ortiz-Bustos et al. (2016). Eight (Spring-2013) and six (Spring2016) seeds (replications) were individually planted in independent pots. The maize variety PR32W86 (Pioneer Hi-Bred Agro Servicios Spain SL) susceptible to late wilt (MolineroRuiz et al., 2010) was used. Seeds were surface-sterilized by immersing them in $10 \%$ sodium hypochlorite for 5-10 $\mathrm{min}$, then thoroughly rinsed in deionized water and incubated in the dark at saturation humidity and $24-28{ }^{\circ} \mathrm{C}$ for $24-48 \mathrm{~h}$, until their radicles were $5-10 \mathrm{~mm}$ long. Monoconidial cultures of isolate HmLT809-S were transferred to potato dextrose agar amended with $300 \mathrm{mg} / \mathrm{l}$ streptomycin sulphate and incubated at $28{ }^{\circ} \mathrm{C}$. The isolate was recovered from a symptomatic plant of maize in Seville province (Spain) in 2009 (OrtizBustos et al., 2016) and has been used in previous works by our research group (Ortiz-Bustos et al., 2016; Tej et al., 2018). A 510-bp sequence of the 5.8S rDNA coding and spacer regions of this isolate is deposited in GenBank under accession no. KP164518 (Ortiz-Bustos et al., 2016). After three days, $9 \mathrm{~mm}$ diameter discs of the actively growing colonies were added to glass bottles containing $200 \mathrm{~g}$ sterilized wheat grains. The bottles were incubated at room temperature for 5 weeks until inoculation. Colonized grains of wheat ( $20 \mathrm{~g})$ were added to $0.5 \mathrm{~L}$ pots containing sterilized soil mixture (sand:silt:peat moss, $2: 1: 2, \mathrm{~V} / \mathrm{V}$ ), to which individual maize seedlings were transplanted $24 \mathrm{~h}$ later. Non- colonized wheat grains were used for the control treatments. After growing for two weeks, plants were transplanted, with the infested soil, to $26 \mathrm{~L}$ pots containing soil mixture (sand:silt:peat moss, $2: 1: 4, \mathrm{~V} / \mathrm{V}$ ) and grown under the same conditions until the end of the experiment.

The experiments were surrounded with two rows of pots of the same size planted with healthy maize to avoid border effects. The border management was the same as that of the experiment plants. An automated weather station located at $500 \mathrm{~m}$ distance from the experiment site monitored the meteorological conditions of the experiments.

This article is protected by copyright. All rights reserved. 
Each pot was fertilized monthly with $13 \mathrm{~g}$ of urea $\left[\mathrm{CO}\left(\mathrm{NH}_{2}\right)_{2}\right]$, starting when the plants were one month-old and until the end of the experiment. Plants were watered as needed. The experiments were conducted from April 3 (inoculation) to July 26 in 2013, and from March 9 (inoculation) to July 7 in 2016, following a complete randomized design. The disease severity (DS) on aboveground parts was evaluated as the percentage of leaf area that showed wilting, necrosis and/or dryness. Dry weights of roots and aboveground parts of each plant were recorded at the end of the experiment, and the harvest index (HI) and Root/Aboveground organs ratio were calculated. The structures considered as aboveground parts were stems, leaves, and cobs (female inflorescences irrespective of developmental stage). Experiments were conducted following a complete randomized design with eight and six replications in Spring-2013 and Spring-2016, respectively. Analyses of variance (ANOVA) were performed for all the variables and Fisher's LSD tests $(\mathrm{P}=0.05)$ were used for comparisons of mean values.

Effect of Magnaporthiopsis maydis on maize under conditions optimal for late wilt. Disease development under two irrigation treatments

Changes in plant growth in response to severe infections by M. maydis, and the effect that water management can have on late wilt development and severity were investigated in two experiments conducted, from April 13 to August 6 in 2015 (experiment Spring-2015) and from July 6 to October 20 in 2016 (experiment Summer-2016), under the semi-natural conditions of an open-air enclosure. The methodology was similar to that described in the previous section, with six replications (plants) per treatment. Plants in these experiments were naturally exposed to a warmer and drier micrometeorological environment with respect to the Spring-2013 and Spring-2016 experiments (Table 1). Germinated seedlings were inoculated 
by transplant to soil infested with HmLT809-S isolate as described above. Inoculations were conducted on April 13 (Spring-2015) and on July 6 (Summer-2016). Also following the same methodology as described above, plants were grown for two weeks in $0.5 \mathrm{~L}$ pots containing infested soil, and afterwards transplanted to $26 \mathrm{~L}$ ones and kept under the same growth conditions until the end of the experiment. Fertilization was conducted as above, and two irrigation treatments were established: a well-irrigated Control treatment designed to prevent any water stress, which consisted of supplying water in $30 \%$ excess of the potential plant evapotranspiration (ET); a deficit treatment, this one designed to maintain a steady water stress and transpiration reduction, supplying $50 \%$ of the plant potential ET. The potential, unstressed ET was calibrated weekly by weighing three control plants on scales at a $24 \mathrm{~h}$ interval. Changes in the evaporative demand for meteorological reasons were accounted for by dividing the average of the weight differences by the reference evapotranspiration $\left(\mathrm{ET}_{0}\right.$, Allen et al., 1998) obtained each day from a weather station located at a 500m distance, on the day of calibration. The unstressed plant evapotranspiration for each day between calibrations was obtained by multiplying this reference value by the $\mathrm{ET}_{0}$ of that day, thus removing errors due to meteorological conditions deviating from the day of calibration. Total amounts of irrigation water provided were $175 \mathrm{~L} /$ plant and $70 \mathrm{~L} /$ plant to the control and deficit treatments, respectively. The experiments were set up as factorial on a completely randomised design with six replications (plants). A border consisting of two rows of pots planted with healthy maize was also set up to ensure that all the experimental plants shared the same uniform radiation environment.

Height and total leaf area were assessed during the vegetative growth of the plants in 2015 . Evaluations of DS were conducted and the Area Under the Disease Progress Curve (AUDPC) was calculated by the trapezoidal integration method of DS (Campbell \& Madden 1990). Dry weights of aboveground parts of each plant were recorded and the HI was calculated. Dry 
weights of roots and the root/aboveground organs ratio were also calculated. Data were subjected to ANOVA and, when significances were found, Fisher's LSD tests $(P=0.05)$ were used for comparisons of mean values of variables for main factors and for their interaction.

\section{Microbiological and molecular characterization of Magnaporthiopsis maydis in} the inoculated plants

In all the experiments the presence of the pathogen in inoculated plants was confirmed by means of microbiological analyses. At the end of each experiment, cross sections from the first internode of the stem of each inoculated and control plant were sampled and stored at room temperature for one month. Each stem section was divided into two-six pieces that were surface-disinfested for $3 \mathrm{~min}$ by immersion in $20 \%$ household bleach (40 g of active chlorine per litre), rinsed in deionized water for $3 \mathrm{~min}$ and air dried. Segments 2 to $4 \mathrm{~mm}$ long of maize tissue were aseptically transferred to petri plates containing potato dextrose agar (PDA). Plates were incubated at $25{ }^{\circ} \mathrm{C}$ for $72 \mathrm{~h}$ in darkness. Colonies were morphologically confirmed by observation under the stereomicroscope.

Diagnostic molecular analyses were also conducted on plants of the Spring-2013 and (Springand Summer-) 2016 experiments. For molecular diagnosis, total genomic DNA from dry stem tissues of inoculated and control plants of all the experiments was individually purified using the i-genomic Plant DNA Extraction Minikit (iNtRON Biotechnology, Sangdaewon-Dong, Korea) according to the manufacturer's instructions. The quality and concentration of DNA samples were determined with a QubitTM 3.0 Fluorometer (InvitrogenTM, Carlsbad CA, USA). Finally, DNA samples were adjusted to a final concentration of $10 \mathrm{ng} / \mu \mathrm{L}$ and stored at $-20{ }^{\circ} \mathrm{C}$ until required. The presence of $M$. maydis in maize tissues was confirmed by using 
the A200 primer set: A200a (forward primer, 5'-CCGACGCCTAAAATACAGGA-3') and A200b (reverse primer: 5'-GGGCTTTTTAGGGCCTTTTT-3'), which amplify a DNA fragment specific of the fungus (Drori et al., 2013). Optimized PCR assays were carried out in a final volume of $25 \mathrm{~mL}$ containing $0.4 \mu \mathrm{M}$ each primer, $800 \mu \mathrm{M}$ dNTPs, $2.5 \mathrm{~mL} \mathrm{10x}$ PCR buffer (800 mM tris-HCl, pH 8.3-8.4 at $25^{\circ} \mathrm{C}, 0.2 \%$ Tween $\left.20 \mathrm{wt} / \mathrm{V}\right), 0.15 \mathrm{U}$ Horse-PowerTaq DNA polymerase (Canvax, Córdoba, Spain), $2.5 \mathrm{mM} \mathrm{MgCl} 2$ and $20 \mathrm{ng}$ of fungal DNA. The following profile was set for amplifications: 2 min initial denaturation at $94{ }^{\circ} \mathrm{C} ; 35$ cycles of $30 \mathrm{~s}$ denaturation at $94{ }^{\circ} \mathrm{C}, 30 \mathrm{~s}$ annealing at $55^{\circ} \mathrm{C}$, and $1 \mathrm{~min}$ of extension at $72{ }^{\circ} \mathrm{C}$; and a final extension step of $5 \mathrm{~min}$ at $72{ }^{\circ} \mathrm{C}$. Mycelial DNA of the fungus grown onto PDA and water were used as positive and negative controls, respectively, of amplification. All reactions were done in a T1 Thermocycler (Whatman Biometra, Göttingen, Germany). Amplification products were separated by horizontal electrophoresis in 1.5 or $2 \%$ agarose gels containing $0.05 \mu \mathrm{l} / \mathrm{ml}$ GoldView Nucleic Acid Stain (Biotech, Beijing, China) and visualized over a UV light source. A 100- to 1,000-bp ladder (Canvax Biotech SL, Cordoba, Spain) was included in the electrophoresis.

\section{Results}

The presence of $M$. maydis in inoculated plants was confirmed in all the microbiological analyses of stem tissues as well as by PCR amplification using the A200 primer set specific to the fungus. A 200 bp band was amplified in DNA samples from inoculated plants of the experiments that were conducted under conditions sub-optimal for late wilt (Fig. 1a, b). This same diagnostic band was observed after DNA amplification of samples from inoculated plants and under full irrigation and moderate stress water regimes in the experiment of Summer-2016 (Fig. 1c, d).

This article is protected by copyright. All rights reserved. 
Effect of Magnaporthiopsis maydis on maize under conditions sub-optimal for late wilt

The Spring-2013 and Spring-2016 experiments were characterized by relatively mild air temperatures (whole crop cycle averages of $22.8{ }^{\circ} \mathrm{C}$ and $20.9^{\circ} \mathrm{C}$ for the Spring-2013 and Spring-2016 experiments, respectively), and rather high humidity (average relative humidity of 54.1\% and 58.4\%; Vapour Pressure Deficit (VPD) of 1.6 and $1.3 \mathrm{kPa}$ for Spring-2013 and Spring-2016, respectively - Table 1).

In both years, the treatment (inoculation or not) significantly affected the aboveground biomass ( $P=0.0120$ and $P=0.0074$ for Spring-2013 and Spring-2016, respectively), as well as the root biomass $(P=0.0020$ and $P=0.0450$ for Spring-2013 and Spring-2016, respectively). Mean values and standard errors of both variables in Spring-2013 and Spring2016 are presented in Table 2 . The root/aboveground biomass ratio was significantly $(P=$ 0.0040) dependent on treatment in Spring-2013 (0.35 and 0.23 for control and inoculated plants, respectively), but this was not observed in Spring-2016 (Table 2). In contrast, a significant $(P=0.0122)$ decrease in yield was recorded in Spring-2016, with the weight of cobs varying from $258.0 \mathrm{~g}$ for the controls to $154.8 \mathrm{~g}$ for the inoculated plants. Although no significant, a small yield decrease was obtained after inoculation in Spring-2013 (Table 2). Of great interest was the finding that $\mathrm{HI}$ was not significantly affected by the treatment factor in either of the two experiments. Average values across treatments were 0.59 in Spring-2013 and 0.67 in Spring-2016 (Table 2). As for visual symptoms of late wilt on leaves, these were not observed either in Spring-2013 or in Spring-2016.

This article is protected by copyright. All rights reserved. 


\section{Effect of Magnaporthiopsis maydis on maize under conditions optimal for late}

wilt. Disease development under two irrigation treatments

In the Spring-2015 and Summer-2016 experiments, meteorological conditions were more demanding on the water conduction systems of the experimental plants than those recorded in Spring-2013 and Spring-2016. The average air temperatures during the crop cycle were higher $\left(26.2{ }^{\circ} \mathrm{C}\right.$ in 2015 and $28.1^{\circ} \mathrm{C}$ during the experiment of summer 2016 , whereas the relative humidity was lower: $45.3 \%$ for Spring-2015 and 43.6\% in Summer-2016. The resulting atmospheric water demand was 2.3 and $2.5 \mathrm{kPa}$ VPD for Spring-2015 and Summer2016, respectively (Table 1).

When aboveground biomass, yield and HI of inoculated and control plants of the Spring-2015 experiment were analysed, significant differences were, in the three cases, associated with both factors: inoculation $(P \leq 0.043)$ and water regime (WR) $(P \leq 0.037)$ but not with their interaction. Mean values and standard errors of the growth and production variables and of the AUDPC in the plants are presented in Figure 2. Aboveground biomass and yield were highest for the fully irrigated maize (irrespective of being inoculated or not), or for the noninoculated plants (regardless of WR treatment). Aboveground dry biomass varied between $367.4 \mathrm{~g}$ per plant (fully irrigated and non- inoculated maize) and $182.7 \mathrm{~g}$ per plant (stressed and inoculated maize). Yield ranged from $118.2 \mathrm{~g}$ to $30.8 \mathrm{~g}$ per plant (for fully irrigated and non-inoculated maize, and water-stressed and inoculated maize, respectively). Noninoculated and water-stressed maize plants, as well as inoculated and fully irrigated plants had intermediate values of aboveground biomass and yield (Fig. 2a, b). When the HI was analysed, all the treatments showed similar values except for the inoculated and deficit irrigated maize, which exhibited a significantly lower value $(0.17$ compared with 0.29 , the latter being the average across the remaining three treatment combinations) (Fig. 2c).

This article is protected by copyright. All rights reserved. 
At the latter stage of the experiment (July 2015), leaf symptoms of late wilt developed in the plants. AUDPC was significantly affected by WR, inoculation and the interaction of both factors $(P<0.0001$ in the three cases). Inoculated and water-stressed plants had the highest AUDPC (1019) and inoculated and fully irrigated plants gave an intermediate value of AUDPC (375). The lowest AUDPC was that of non- inoculated and fully irrigated plants (48) (Fig. 2d). Finally, when the growth of the plants was analysed in 2015 by means of height and leaf area measurements, significant differences in both variables were associated with WR at all time points (Fig. 3). However, the effect of full irrigation on plant height was scant in the first month and a half of the experiment, and thus inoculated plants showed the significantly $(P \leq 0.0352)$ lowest values of plant height (Fig. 3a). In contrast, the effect of treatment on the total leaf area of the plants was significant during almost the whole experiment $(P \leq 0.0012)$. The total leaf area of non- inoculated and fully irrigated plants was the most extensive at all times, while that of inoculated and water-stressed plants was the smallest. Inoculated and fully irrigated plants, together with non- inoculated and waterstressed plants, had intermediate values of total leaf area, particularly between 43 and 49 DAI (Fig. 3b).

The meteorological conditions of the Summer-2016 experiment configured a waterdemanding environment sharing with that of Spring-2015 the assumption of being optimal for the development of $M$. maydis symptoms. Mean values and standard errors of the variables studied under both factors (inoculation with the fungus and water regime) are included in Table 3. For clarity of Table 3, values of statistical significances and the LSD for mean comparisons are presented in Table 4 . Inoculated plants showed significantly $(P \leq 0.0266)$ lower aboveground and root biomasses, and a Root/Aboveground ratio, in comparison with the non- inoculated ones. Irrigation significantly $(P \leq 0.0200)$ affected the aboveground biomass, yield, HI and AUDPC of the plants (Table 3). Similar to what was observed in the 
Spring-2015 experiment, both main factors: inoculation and WR, had a significant impact on growth, production and/or disease variables in Summer-2016, but their interaction did not (Table 4). Aboveground and root biomass values ranged from $281.5 \mathrm{~g}$ and $31.04 \mathrm{~g}$, respectively, for non- inoculated and fully irrigated plants to $200.79 \mathrm{~g}$ and $52.10 \mathrm{~g}$, averaged across the three remaining combinations of treatments, respectively (Table 3). Although root biomass was lesser upon inoculation, the differences between inoculated and control plants under full irrigation were much greater (13 and $31 \mathrm{~g}$ respectively) than under moderate stress (17 and $21 \mathrm{~g}$, respectively). With regard to the root/aboveground ratio of biomass, it was significantly at its lowest in inoculated and fully irrigated plants $(0.06$, as compared to 0.11 , averaged across the plants under the remaining treatments). Plants yielded most in the noninoculated and fully irrigated treatment $(159.34 \mathrm{~g})$ and least in the inoculated and waterstressed one (92.29 g), with intermediate values in the other two treatments. When the HI was analysed, the highest and lowest values were those of the inoculated and fully irrigated plants (0.6335), and non-inoculated and water-stressed plants (0.4640). Finally, the AUDPC ranged from 0.16 (average for fully irrigated maize) to 20.62 (average for water-stressed maize) (Table 3).

\section{Discussion}

This research shows that $M$. maydis exerts its initial effect on the roots of the plants, whose weight decreases clearly under both environmentally favourable and unfavourable conditions for disease development. Significant reductions in maize root weight have already been associated with $M$. maydis infections, but only in the case of optimal conditions for late wilt (García-Carneros et al., 2012; Ortiz-Bustos et al., 2015; 2016). In this work we demonstrate that root and aboveground biomass production is affected by the pathogen in the absence of symptoms of wilting, necrosis and/or dryness of leaves (under sub-optimal conditions for late 
wilt development). That was the case of Spring-2013 and Spring-2016 experiments, in which characteristic aboveground symptoms did not appear in inoculated plants in spite of growth and yield variables being clearly altered by the fungus. Sub-optimal conditions for late wilt like those of experiments Spring-2013 and Spring-2016 (i.e. not very high air temperature and relatively high air humidity) should help plants suffering from an impaired water transport system due to the infection to transpire close to the potential rate, so that less severe symptoms would be expected for plants infected by M. maydis.

On the other hand, when air temperatures and humidity were optimal for disease (experiments Spring-2015 and Summer-2016), the changes in growth and production was the most important effect of $M$. maydis, although leaf symptoms also became apparent in inoculated plants. Associations between reproductive growth and disease expression are well documented in plants. In the work by Hartman and Fletcher (1991), leaf and stem symptoms of Fusarium crown and root rot caused by Fusarium oxysporum f. sp. radicis-lycopersici did not appear until fruit harvest time. As in the case of maize late wilt, foliar symptoms in melon (Cucumis melo L.) infected by the soil-borne fungus Monosporascus cannonballus result from damage to the root system, which occurs much earlier than sudden wilt or collapse (Pivonia et al., 2002). Thus, our results suggest that maize late wilt is, at least partly, the consequence of the negative effects of $M$. maydis on the growth and size of the plant root system. Under conditions of high temperature and low humidity, an impaired root system may be unable to supply the necessary flow to meet the leaves transpiring requirements, thus generating wilt and then damage by tissue desiccation. Although this hypothesis needs further confirmation, it would explain why severe yield damage is usually found in countries with warm and dry climates during the growing season.

This article is protected by copyright. All rights reserved. 
The effect of water availability on disease incidence and severity is difficult to determine and highly dependent on the pathogen's nature (Boyer, 1995). In the present study, the expression of the disease caused by $M$. maydis in the inoculated plants was strongly influenced by the water availability (full irrigation compared to moderate stress). Moreover, symptoms of wilting and leaf necrosis remained unnoticed at a macroscopical level in fully irrigated maize, although plant biomass decreases still occurred. Hypotheses proposing that disease symptoms are more severe under stress conditions have been successfully tested in the case of bacteria, such as Xylella fastidiosa affecting Virginia creeper (Parthenocissus quinquefolia) (McElrone et al., 2001) or Xanthomonas campestris pv. musacearum, causal agent of banana wilt (Ochola et al., 2015), but also in that of fungal diseases, like Verticillium wilt of eggplant (Bletsos et al., 1999) or pistachio (Saadatmand et al., 2008), or Ceratocystis wilt caused by Ceratocystis fimbriata in mango (Rezende da Silva et al., 2017). An important dependence of late wilt on the water status of maize has been suggested under field conditions, with decreased disease severities under flood-fallowing (Samra et al., 1966). Our results are in agreement with the observations by Samra et al. (1966), although scant late wilt severities in the field can also be the consequence of sclerotia degradation due to high soil moisture content (Bergstrom et al., 2008).

It is noteworthy that when growth, yield and disease variables were analysed, no significant interactions between WR and inoculation were found, meaning that inoculated and control plants reacted similarly to WR. The only exception was root biomass. Magnaporthiopsis maydis affected the roots more severely, as compared with the controls, in the case of fully irrigated plants than in those of plants subjected to moderate stress (experiment Summer2016). This finding suggests that, in the absence of water stress, M. maydis causes massive root destruction and alters the growth of infected plants, whereas the roots of healthy 
(control) maize plants develop normally. In the presence of water stress infection of roots by M. maydis seems to have little effect.

It is of interest to note that the pathogen infection seems to affect the Root/Aboveground biomass ratio to a greater extent when the plants grow under good water conditions than under deficit irrigation (experiment Summer-2016). A possible explanation to this finding could be that, with the soil being frequently wetted, a reduced growth of the infected root system may still be able to provide the water uptake needed to maintain a sufficient water potential in the plant canopy, thus maintaining an adequate growth in the aboveground organs and, therefore, leading to a lower Root/Aboveground biomass ratio. Conversely, under moderate water stress, the infected, smaller or impaired root system fails to match the aboveground water demand; the consequent canopy growth reduction acts like a feedback system over the plant growth, rebalancing the proportion between roots and canopy (with lower total biomass). This hypothetical mechanism of action deserves further research but, if true, one can expect that, under steady good soil water conditions, the infected crop may end the cycle asymptomatically and the disease may go undetected, although some reduction in yield and above-ground biomass can occur. This is in agreement with reports that environmental conditions can mask late wilt expression (Singh \& Siradhana, 1987; Bergstrom et al., 2008).

However, our data show that $M$. maydis unquestionably affects the root system's growth and function to a great extent, and the damage (expressed as root growth reduction) seems to occur before any of the usual symptoms on the above-ground plant become perceivable. It is thus conceivable that infection of the maize root system by $M$. maydis starts early in the season and gradually worsens the root's functioning, as happens in melon plants infected by M. cannonballus (Pivonia et al., 1999). It remains unknown to what extent wilt symptoms in maize (which appear subsequently to root infection by $M$. maydis) are caused by the 
restriction of xylem water flow imposed by blockage of xylem vessels with extracellular polysaccharides, tyloses or air embolisms as reported in other vascular diseases like those caused by Verticillium dahliae or Fusarium oxysporum (Beckman, 1987; Pegg and Brady, 2002; Yadeta and Thomma, 2013), or by toxins causing membrane injury and water leakage, like fusaric acid in F. oxysporum infections (Wang et al., 2014). Vascular occlusion and cavitation in xylem elements have nonetheless been proposed as being the cause of wilting and death of M. maydis infected maize (Abd El-Rahim et al., 1998; Degani et al., 2015). Our results point to the root (and probably root xylem) as the first and main site of action for $M$. maydis damage creation.

In conclusion, we found that $M$. maydis can infect maize and significantly affect the plant growth under unfavourable conditions for symptom development. In this situation, the fungus is able to penetrate the roots of the plants, grow inside them and even reach inner stem tissues at the first internode as revealed by our molecular results. Under these circumstances, roots and aboveground organs, even the yield, result altered despite the fact that leaf symptoms are not visible. Secondly, our results show how growth and production variables of infected maize can be affected by water regimes when air temperature and humidity are favourable for late wilt development. Finally, the novelty of our research also lies in the fact that we provide clues indicating that the root system may well be the first and most important target organ for this disease. Infection of the maize root system by $M$. maydis early in the season not only results in late wilt symptoms and yield reduction, but also seems to alter root functioning all throughout the crop season. Whether the leaf wilting and other symptoms are direct effects of the pathogen on the above-ground organs or are indirectly caused by the root system impairment or underdevelopment is an issue for further research. Although plants can become predisposed to pathogen attack when they have been weakened by water deficiency, limited water availability after the establishment of the infection, like what we observed, also 
increases subsequent disease development and damage (Boyer, 1995). In fact, the symptoms (leaf wilting) and the final effects on yield are all similar to those of water stress, the same as can be expected in plants with underdeveloped root systems in high water-demanding environments. This could be associated with the concurrent occurrence of a high evaporative demand and M. maydis in areas like India, Egypt, and the south of the Iberian Peninsula mostly dry environments - where late wilt is the main biotic constraint to maize grain production. More importantly, the impacts of climate change include weather pattern alterations, with higher frequencies of extreme events, and modifications in rainfall regimes, leading to increased risks of drought and floods (Houghton et al., 2001). Increased and/or new late wilt outbreaks could be expected in maize- growing areas with increased temperatures and drought events associated with climate change (Eastburn et al., 2011; Bebber, 2015).

\section{Acknowledgements}

This research was partially supported by the Spanish National Research Council (CSIC) (PIE200940I120). Excellent technical assistance from A.B. García-Carneros, I. Calatrava and J.L. Vázquez-Taguas is gratefully acknowledged. The authors have no conflict of interest to declare.

This article is protected by copyright. All rights reserved. 


\section{References}

Abd El-Rahim MF, Fahmy GM, Fahmy ZM, 1998. Alterations in transpiration and stem vascular tissues of two maize cultivars under conditions of water stress and late wilt disease. Plant Pathology 47, 216-223.

Allen RG, Pereira JS, Raes D, Smith M, 1998. Crop evapotranspiration: guidelines for computing crop water requirements. Rome: Food and Agriculture Organization of the United Nations.

Bebber, D.P. 2015. Range-expanding pests and pathogens in a warming World. Annual Review of Phytopathology 53, 335-356.

Beckman CH, 1987. The Nature of Wilt Diseases of Plants. St. Paul, MN, USA: APS Press.

Bergstrom G, Leslie J, Huber D et al., 2008. Recovery plan for late wilt of corn caused by Harpophora maydis syn. Cephalosporium maydis. Washington DC, USA: National Plant Disease Recovery System.

Bletsos FA, Thanassoulopoulos CC, Roupakias DG, 1999. Water stress and Verticilium wilt severity on eggplant (Solanum melogena L.). Journal of Phytopathology 147, 243-248.

Boyer JS, 1995. Biochemical and biophysical aspects of water deficits and the predisposition to disease. Annual Review of Phytopathology 33, 251-274.

Campbell CL, Madden LV, 1990. Introduction to Plant Disease Epidemiology. New York, USA: John Wiley \& Sons.

Degani O, Dor S, Movshowitz D et al., 2018. Effective chemical protection against the maize late wilt causal agent, Harpophora maydis, in the field. PloS One 13, e0208353.

Degani O, Weinberg T, Graph S, 2014. Chemical control of maize late wilt in the field. Phytoparasitica 42, 559-570.

Drori R, Sharon A, Goldberg D et al., 2013. Molecular diagnosis for Harpophora maydis, the cause of maize late wilt in Israel. Phytopathologia Mediterranea 52, 16-29.

This article is protected by copyright. All rights reserved. 
Eastburn DM, McElrone AJ, Bilgin DD, 2011. Influence of atmospheric and climatic change on plant-pathogen interactions. Plant Pathology 60, 54-69.

El-Mehalawy AA, Hassanein NM, Khater HM et al., 2004. Influence of maize root colonization by rhizosphere actinomycetes and yeast fungi on plant growth and on the biological control of late wilt disease. International Journal of Agriculture and Biology $\mathbf{6}$, $599-605$.

El-Shafey HA, Claflin LE, 1999. Late wilt. In: White DG, ed. Compendium of Corn Diseases. St Paul, MN, USA: APS Press, 43-44.

García-Carneros AB, Girón I, Molinero-Ruiz L, 2012. Aggressiveness of Cephalosporium maydis causing late wilt of maize in Spain. Communications in Agricultural and Applied Biological Sciences 77, 173-179.

Hall R, MacHardy WE, 1981. Water relations. In: Mace ME, Bell AA, Beckman CH, eds. Fungal wilt diseases of plants. New York, NY, USA: Academic Press, 255-298.

Hartman JR, Fletcher JT, 1991. Fusarium crown and root rot of tomatoes in the UK. Plant Pathology 40, 85-92.

Houghton JT, Ding Y, Griggs DJ, et al., 2001. Climate Change 2001: The Scientific Basis. Contribution of Working Group I to the Third Assessment Report of the Intergovernmental Panel on Climate Change. Cambridge, UK: Cambridge University Press.

McElrone AJ, Sherald JL, Forseth IN, 2001. Effects of water stress on symptomatology and growth of Parthenocissus quinquefolia infected by Xylella fastidiosa. Plant Disease 85, $1160-1164$

Molinero-Ruiz ML, Melero-Vara JM, Mateos A, 2010. Cephalosporium maydis, the cause of late wilt in maize, a pathogen new to Portugal and Spain. Plant Disease 94, 379.

This article is protected by copyright. All rights reserved. 
Ochola D, Ocimati W, Tinzaara W et al., 2015. Effects of water stress on the development of banana xanthomonas wilt disease. Plant Pathology 64, 552-558.

Ortiz-Bustos CM, García-Carneros AB, Molinero-Ruiz L, 2015. La marchitez tardía del maíz (Zea mays L.) causada por Cephalosporium maydis en la Península Ibérica, y otros hongos asociados. Summa Phytopathologica, doi: 10.1590/0100-5405/1998.

Ortiz-Bustos CM, Testi L, García-Carneros AB, Molinero-Ruiz L, 2016. Geographic distribution and aggressiveness of Harpophora maydis in the Iberian peninsula, and thermal detection of maize late wilt. European Journal of Plant Pathology, doi: $10.1007 / \mathrm{s} 10658-015-0775-8$

Pegg GF, Brady BL, 2002. Verticillium Wilts. Wallingford, UK: CABI Publishing.

Pivonia S, Cohen R, Katan J, Kigel J, 2002. Effect of fruit load on the water balance of melon plants infected with Monosporascus cannonballus. Physiological and Molecular Plant Pathology 60, 39-49.

Rezende da Silva SD, Lopes de Siqueira D, Chamhum Salomao LC et al., 2017. Ceratocystis wilt in 'Ubá' and 'Dura' mango trees under water deficit. Revista Brasileira de Fruticultura 39, e-441. http://dx.doi.org/10.1590/0100-29452017441.

Saadatmand AR, Banihashemi Z, Sepaskhah AR, Maftoun M, 2008. Soil salinity and water stress and their effect on susceptibility to Verticillium wilt disease, ion composition and growth of pistachio. Journal of Phytopathology 156, 287-292.

Sabet KA, Zaher AM, Samra AS, Mansour IM, 1970a. Pathogenic behavior of Cephalosporium maydis and C. acremonium. Annals of Applied Biology 66, 257-263.

Sabet KA, Samra AS, Mansour, IM, 1970b. Saprophytic behaviour of Cephalosporium maydis and C. acremonium. Annals of Applied Biology 66, 265-271.

Samra AS, Sabet KA, Hingorani MK, 1963. Late wilt disease of maize caused by Cephalosporium maydis. Phytopathology 53, 402-406.

This article is protected by copyright. All rights reserved. 
Samra AS, Sabet KA, Abdel-Rahim MF, 1966. Effect of soil conditions and cultural practices on infection with stalk rots. In: Samra AS, Sabet KA, eds. Investigations on Stalk-rot Disease of Maize. Cairo, Egypt: U.A.R. Ministry of Agric. Government Printing Offices, $117-164$.

Singh SD, Siradhana BS, 1987. Influence of some environmental conditions on the development of late wilt of maize induced by Cephalosporium maydis. Indian Journal of Mycology and Plant Pathology 17, 1-5.

Tej R, Rodríguez-Mallol C, Rodríguez-Arcos R et al., 2018. Inhibitory effect of Lycium europaeum extracts on phytopathogenic soilborne fungi and the reduction of late wilt in maize. European Journal of Plant Pathology, https://doi.org/10.1007/s10658-018-1469-9.

Wang M, Ling N, Dong X et al., 2014. Effect of fusaric acid on the leaf physiology of cucumber seedlings. European Journal of Plant Pathology 138, 103-112.

Yadeta KA, Thomma BPHJ, 2013. The xylem as battleground for plant hosts and vascular wilt pathogens. Frontiers in Plant Science 4, 97. doi: 10.3389/fpls.2013.00097

Zeller KA, Ismael AM, El-Assiuty EM et al., 2002. Relative competitiveness and virulence of four clonal lineages of Cephalosporium maydis from Egypt toward greenhouse-grown maize. Plant Disease 86, 373-378.

This article is protected by copyright. All rights reserved. 
Table 1. Temperature and humidity conditions during the crop cycle of the experiments

\begin{tabular}{llllll}
\hline Experiment & $\begin{array}{l}\text { Air temp. } \\
\left({ }^{\circ} \mathrm{C}\right)\end{array}$ & $\begin{array}{l}\text { Max. temp. } \\
\left({ }^{\circ} \mathrm{C}\right)\end{array}$ & $\begin{array}{l}\text { Min. temp. } \\
\left({ }^{\circ} \mathrm{C}\right)\end{array}$ & $\begin{array}{l}\text { RH } \\
(\%)\end{array}$ & $\begin{array}{l}\text { VPD }^{\mathrm{b}} \\
(\mathrm{kPa})\end{array}$ \\
\hline Spring-2013 & 22.8 & 30.7 & 14.8 & 54 & 1.6 \\
Spring-2015 & 26.2 & 35.2 & 16.4 & 45 & 2.3 \\
Spring-2016 & 20.9 & 28.3 & 13.9 & 58 & 1.3 \\
Summer-2016 & 28.1 & 37.0 & 19.5 & 43 & 2.5 \\
\hline
\end{tabular}

a Air temperature, maximum temperature, minimum temperature, relative humidity (RH) and VPD are averaged across the crop cycle.

${ }^{\mathrm{b}}$ VPD $=$ Vapour Pressure Deficit of the atmosphere. 
Table 2. Effect of Magnaporthiopsis maydis on maize, expressed as dry weights of different plant organs, harvest index (HI), weight ratio and yield, after inoculation and growth under semi-natural conditions in the Spring-2013 and Spring-2016 experiments

Spring-2013 Spring-2016

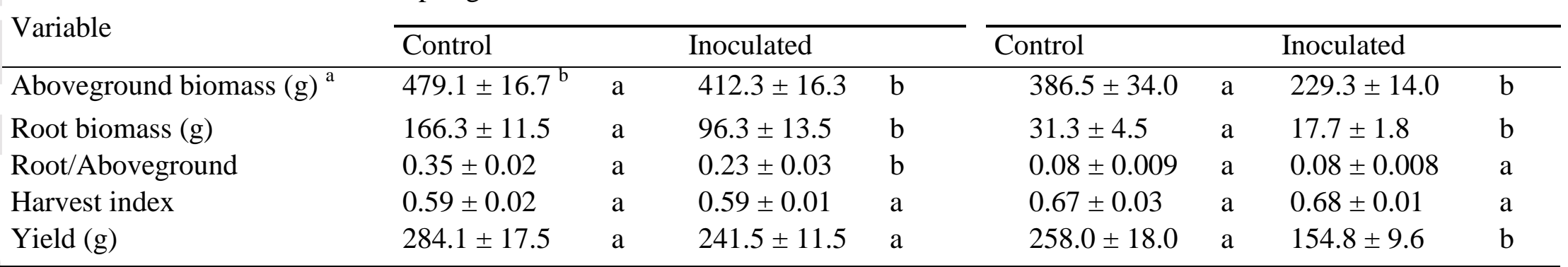

${ }^{a}$ Aboveground biomass is considered as biomass of leaves, stems and cobs.

${ }^{\mathrm{b}}$ Mean values of eight replications and their standard errors. When followed by different letters, they are significantly different according to the least significant difference test $(P=0.05)$.

This article is protected by copyright. All rights reserved. 
Table 3. Effect of Magnaporthiopsis maydis (control and inoculated) and two water regimes (normal, full irrigation; deficit, moderate stress) on dry weights of different plant organs, weight ratio, yield, harvest index and Area Under Disease Progress Curve (AUDPC) of maize plants grown under semi-natural conditions in summer of 2016 (Summer-2016 experiment)

\begin{tabular}{|c|c|c|c|c|}
\hline \multirow{2}{*}{ Variable } & \multicolumn{2}{|l|}{ Control } & \multicolumn{2}{|l|}{ Inoculated } \\
\hline & Normal & Deficit & Normal & Deficit \\
\hline Aboveground biomass $(\mathrm{g})^{\mathrm{a}}$ & $281.49 \pm 21.54$ & $202.99 \pm 24.18$ & $225.05 \pm 11.58$ & $174.33 \pm 11.83$ \\
\hline Root biomass (g) & $31.04 \pm 3.99$ & $21.49 \pm 3.11$ & $13.34 \pm 1.65$ & $17.27 \pm 2.20$ \\
\hline Root/Aboveground & $0.1093 \pm 0.01$ & $0.1119 \pm 0.01$ & $0.0599 \pm 0.01$ & $0.1038 \pm 0.02$ \\
\hline Yield (g) & $159.34 \pm 14.45$ & $100.23 \pm 19.49$ & $142.66 \pm 8.94$ & $92.29 \pm 15.23$ \\
\hline Harvest index & $0.5640 \pm 0.02$ & $0.4640 \pm 0.06$ & $0.6335 \pm 0.02$ & $0.5059 \pm 0.07$ \\
\hline AUDPC & $0.31 \pm 0.31$ & $18.44 \pm 5.73$ & $0.00 \pm 0.00$ & $22.81 \pm 8.23$ \\
\hline
\end{tabular}

${ }^{a}$ Aboveground biomass, considered as biomass of leaves, stems and cobs.

${ }^{\mathrm{b}}$ Mean values and standard errors of six replications.

This article is protected by copyright. All rights reserved. 
Table 4. Effect of Magnaporthiopsis maydis (Mm), two water regimes (WR) and their interaction on growth, production and late wilt of maize, expressed as values of significance after analyses of variance and critical least significant difference values for mean comparisons, in an experiment conducted under semi-natural conditions in summer of 2016 (Summer-2016 experiment)

\begin{tabular}{|c|c|c|c|}
\hline \multirow{2}{*}{ Variable } & \multicolumn{2}{|c|}{ Significance $^{a}$} & \multirow{2}{*}{$\begin{array}{l}\text { Critical Least Significant } \\
\text { Difference (LSD) value }\end{array}$} \\
\hline & Source $^{b}$ & Value of $P$ & \\
\hline \multirow[t]{3}{*}{ Aboveground biomass (g) } & $\mathrm{Mm}$ & 0.0266 & 37.245 \\
\hline & WR & 0.0014 & 37.245 \\
\hline & $\mathrm{Mm} \times \mathrm{WR}$ & ns & - \\
\hline \multirow[t]{3}{*}{ Root biomass (g) } & $\mathrm{Mm}$ & 0.0007 & 5.8959 \\
\hline & WR & ns & - \\
\hline & $\mathrm{Mm} \times \mathrm{WR}$ & 0.0265 & 8.3381 \\
\hline \multirow[t]{3}{*}{ Root/Aboveground } & $\mathrm{Mm}$ & 0.0278 & 0.0254 \\
\hline & WR & ns & - \\
\hline & $\mathrm{Mm} \times \mathrm{WR}$ & $\mathrm{ns}$ & - \\
\hline \multirow[t]{3}{*}{ Yield (g) } & $\mathrm{Mm}$ & $\mathrm{ns}$ & - \\
\hline & WR & 0.0011 & 30.736 \\
\hline & $\mathrm{Mm} \times \mathrm{WR}$ & ns & - \\
\hline \multirow[t]{3}{*}{ HI } & $\mathrm{Mm}$ & ns & - \\
\hline & WR & 0.0200 & 0.0945 \\
\hline & $\mathrm{Mm} \times \mathrm{WR}$ & $\mathrm{ns}$ & - \\
\hline \multirow[t]{3}{*}{ AUDPC } & $\mathrm{Mm}$ & $\mathrm{ns}$ & - \\
\hline & WR & 0.0003 & 10.274 \\
\hline & $\mathrm{Mm} \times \mathrm{WR}$ & ns & - \\
\hline
\end{tabular}

${ }^{a}$ Only significant values of $P$ are shown.

${ }^{\mathrm{b}}$ Sources: Mm (control and inoculation), WR (full irrigation and moderate stress), interaction of both factors.

${ }^{c}$ Significance level for LSD, $P=0.05$.

This article is protected by copyright. All rights reserved. 
Conditions sub optimal for late wilt (Spring-2013 and Spring-2016)

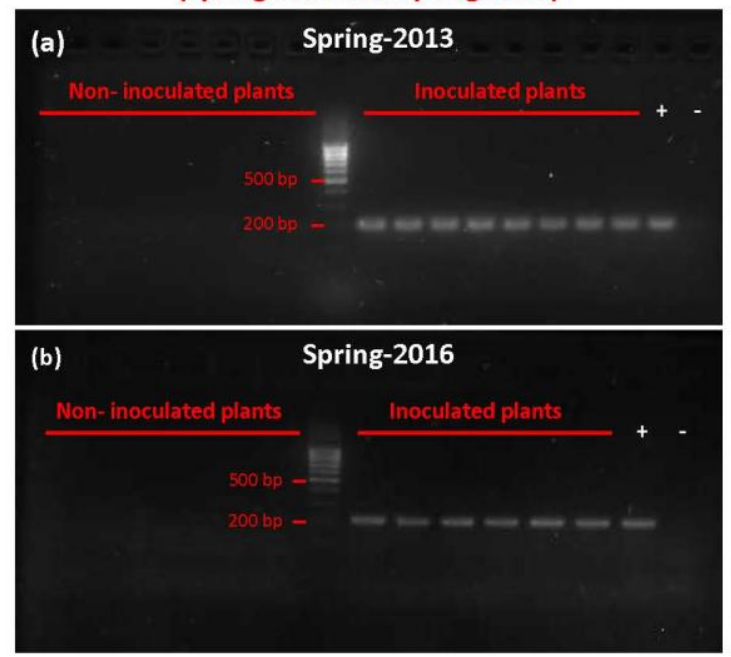

Conditions optimal for late wilt (Summer-2016)

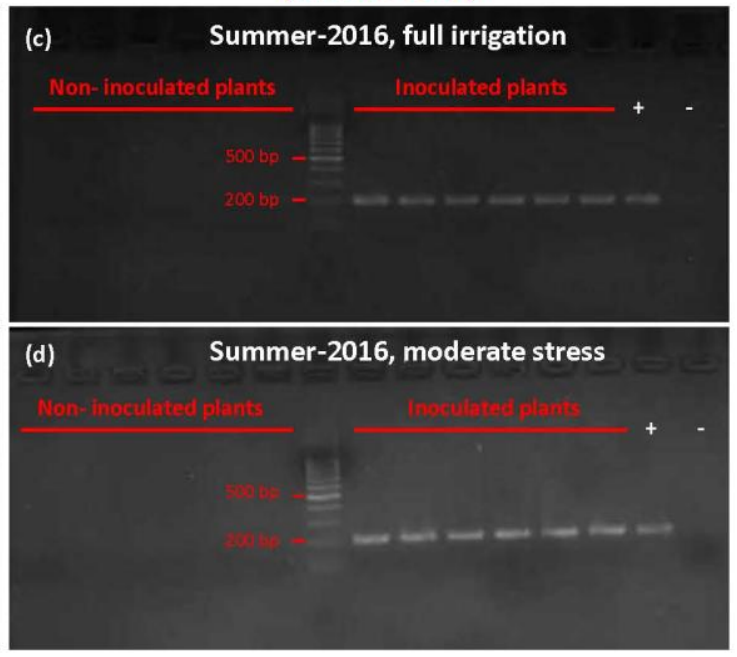

Figure 1 Molecular confirmation of the presence of Magnaporthiopsis maydis in inoculated maize by a 200-bp amplicon (lanes to the right of DNA ladder) as compared to its absence in non- inoculated plants (lanes to the left of DNA ladder), under conditions sub optimal (left panels) or optimal (right panels) for the disease. Molecular analyses were not conducted in the experiment of Spring-2015. (a) lanes of sixteen replications (plants) of the Spring-2013 experiment, (b) lanes of twelve replications (plants) of the Spring-2016 experiment. (c) and (d) lanes of twelve replications (plants) of the Summer-2016 experiment under full irrigation and moderate stress, respectively. Positive and negative controls, corresponding to the last lanes, are indicated.

This article is protected by copyright. All rights reserved. 

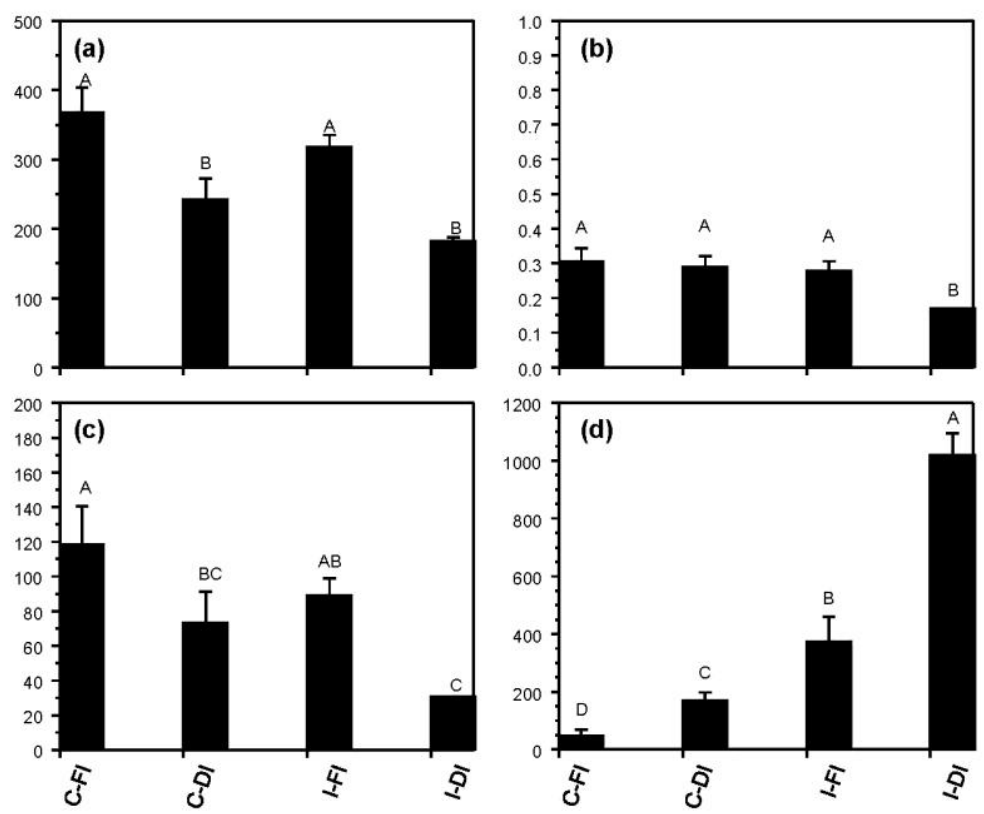

Figure 2 Effect of inoculation with Magnaporthiopsis maydis (control C; inoculated I) and water regime (full irrigation FI; moderate stress, deficit irrigation DI) in plants of maize grown in shade-house in 2015. (a) aboveground biomass, (b) harvest index, (c) yield, (d) Area Under Disease Progress Curve. In all the panels bars with different letters are significantly different $(P \leq 0.05)$ according to Fisher's protected least significant difference tests. Vertical bars represent the standard error of the mean of six replications.

This article is protected by copyright. All rights reserved. 

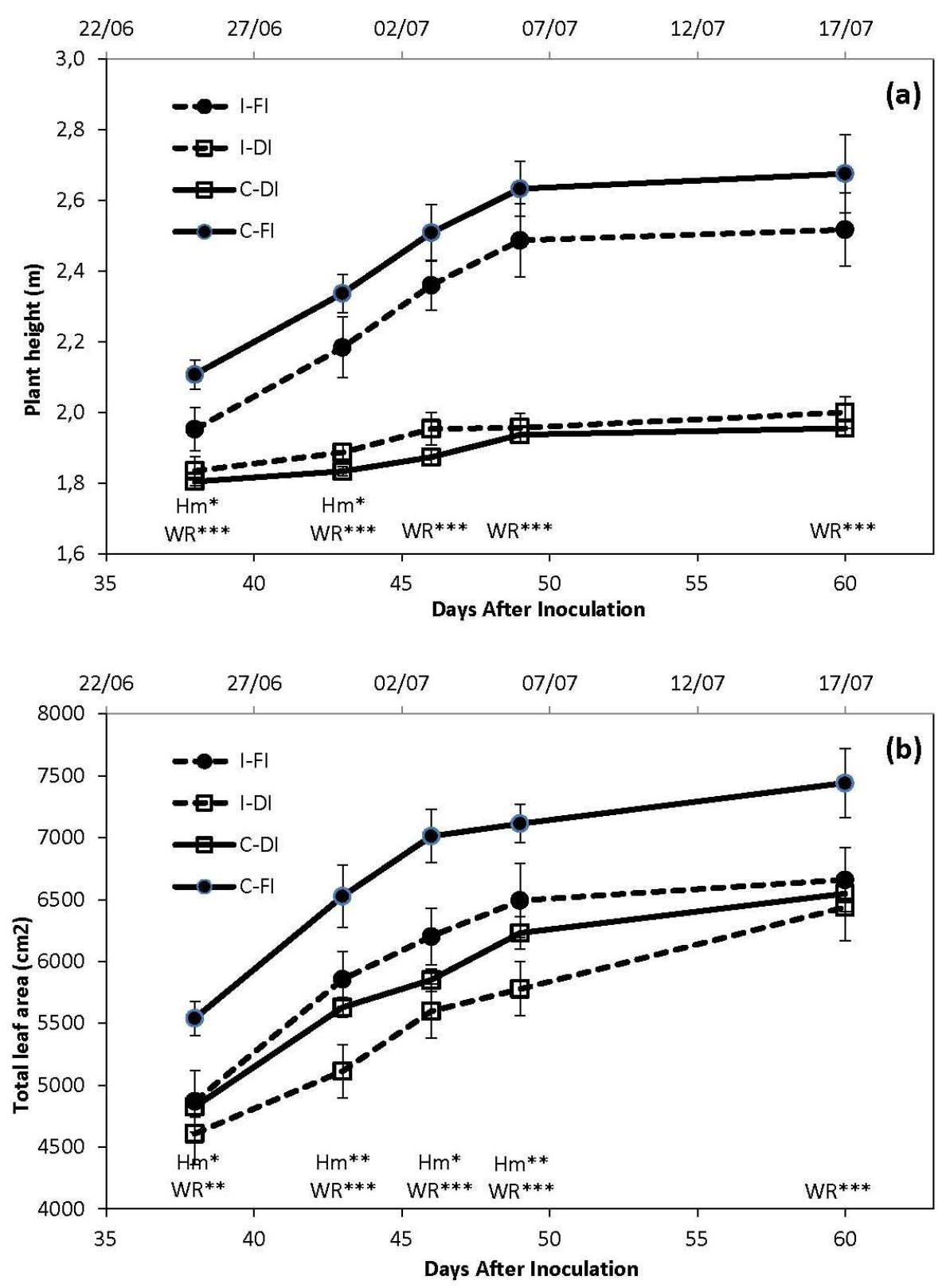

Figure 3 Time series of plant height (a) and total leaf area (b) in control plants (solid lines, C) and in plants of maize inoculated with one isolate of Magnaporthiopsis maydis (Hm) (dashed lines, I) and grown in shade-house under two different water regimes (WR): full irrigation (full dots, FI) and moderate stress deficit irrigation (empty squares, DI) in the spring of 2015. In both panels significant effects of Hm and WR are indicated, their interaction being not significant at any of the time points. Vertical bars represent the standard error of the mean of six replications.

This article is protected by copyright. All rights reserved. 